\title{
Start-up strategies of an experimental fuel processor
}

\author{
Yih-Hang Chen ${ }^{\mathrm{a}}$, Cheng-Ching Yu ${ }^{\mathrm{b}, *}$, Yen-Chun Liu ${ }^{\mathrm{c}}$, Chiou-Hwang Lee ${ }^{\mathrm{c}}$ \\ ${ }^{a}$ Energy and Environmental Laboratory, Industrial Technology Research Institute, Hsinchu 300, Taiwan \\ ${ }^{\mathrm{b}}$ Department of Chemical Engineering, National Taiwan University, Taipei 106-17, Taiwan \\ ${ }^{\mathrm{c}}$ Materials and Chemical Laboratory, Industrial Technology Research Institute, Hsinchu 300, Taiwan
}

Received 25 January 2006; received in revised form 9 March 2006; accepted 10 March 2006

Available online 25 April 2006

\begin{abstract}
In this work, cold start-up of a methane fuel processor is explored. The experimental fuel processor is intended to provide hydrogen for a proton exchange membrane (PEM) fuel cell for the power generation $(3 \mathrm{kWe})$. A dynamic model describing a series of reactors, the reformer, three water-gas shift reactors, and preferential reactor is constructed. Two important factors for rapid start-up are identified: speed of temperature front propagation and acceptable CO concentration. Steady-state analyses reveal that the fuel feed flow rate with fixed steam-to-carbon and air-to-carbon ratios is an ideal manipulated variable. Considering both large initial heat flux and gradual transition back to nominal operation, the shape of feed manipulation is determined. With the feed scenario available, the fuel processor start-up can be formulated as a constrained optimization problem and can be solved numerically. From optimization result, a heuristic is generated for rapid start-up of a fuel processor. This leads to a $25 \%$ improvement in the start-up time. Finally, issues of design modification are explored for further reduction in the start-up time.
\end{abstract}

(C) 2006 Elsevier B.V. All rights reserved.

Keywords: Fuel processor; Start-up; Control; Autothermal reforming; Modeling; Steam reforming

\section{Introduction}

Fuel cell systems offer high potential for efficiency and reduced emissions in power generation [1]. The proton exchange membrane fuel cell (PEMFC) is one of the most popular fuel cell systems in which fuels such as methanol or methane is converted to hydrogen rich syn-gas in a reformer and which is subsequently used in the fuel cell stack. In addition to the reformer, a series of $\mathrm{CO}$ reducing steps, water gas shift reactions and preferential oxidation reactions were taken to keep $\mathrm{CO}$ concentration below $100 \mathrm{ppm}$ before the syn-gas entering the cell stack. This combination constitutes the entire fuel processor [2]. A dynamic model is essential for the fuel processor operation for the following reasons: (1) discriminating control system design for improved load rejection, and (2) evaluating start-up strategies for fast start-up.

Extensive literature has examined various aspects of fuel processor systems for hydrogen rich syn-gas production which include overviews of the fuel processing technology [3-8], in which the reforming technology of hydrocarbon fuels is still the

\footnotetext{
* Corresponding author. Tel.: +8862 3365 1759; fax: +8862 23623040 .

E-mail address: ccyu@ ntu.edu.tw (C.-C. Yu).
}

major focus. Steady-state simulations are often performed for sensitivity analyses in the design and operation phases of the fuel processor [9-12]. Studies on dynamic behavior of the fuel processor have received some attention lately, and typically the relationships between feed conditions and dynamic responses were explored in $[13,14]$. The start-up dynamics was explored in [15] in order to devise a more efficient start-up strategy.

The objective of this work is to construct a dynamic model for a methane fuel processor and control structure can evaluate the performance at start-up stage. The remainder of this paper is organized as follows. Section 2 describes process and modeling aspects of the fuel processor. Sensitivities of operating parameters are explored in Section 3, followed by start-up strategy and evaluation in Section 4. Conclusion is drawn in Section 5.

\section{Process studied}

An experimental methane fuel processor is constructed to generate hydrogen for $3 \mathrm{kWe}$ fuel cell application. Fig. 1 shows the schematic of the fuel processor system with corresponding dimensions (marked in number with the unit of $\mathrm{cm}$ ). The reactants, methane, air, and water, pass through two heat exchangers right after entering the system as shown in the upper left corner 


\begin{tabular}{|c|c|}
\hline \multicolumn{2}{|c|}{ Nomenclature } \\
\hline$C_{p}$ & heat capacity of the gas $\left(\mathrm{kJ} \mathrm{mol} \mathrm{K}^{-1}\right)$ \\
\hline$C_{p, \mathrm{~S}}$ & heat capacity of the carrier $\left(\mathrm{kJ} \mathrm{mol} \mathrm{K}^{-1}\right)$ \\
\hline$C_{p \mathrm{~W}}$ & $\begin{array}{l}\text { heat capacity of the metal reforming reactor wall } \\
\left(\mathrm{kJ} \mathrm{mol} \mathrm{K} \mathrm{K}^{-1}\right)\end{array}$ \\
\hline$D_{\mathrm{I}}$ & inner-diameter of the reactor $(\mathrm{cm})$ \\
\hline$D_{\mathrm{o}}$ & outer-diameter of the reforming reactor $(\mathrm{cm})$ \\
\hline$F$ & total molar flow rate $\left(\mathrm{mol} \mathrm{min}^{-1}\right)$ \\
\hline$h$ & pulse height \\
\hline$\Delta H_{\mathrm{R}}$ & heat of reaction of reaction $\left(\mathrm{kJ} \mathrm{mol}^{-1}\right)$ \\
\hline$k_{\text {cond }}$ & $\begin{array}{l}\text { thermal conductivity of the metal reactor wall } \\
\left(\mathrm{kJ} \mathrm{min}{ }^{-1} \mathrm{~cm}^{-1} \mathrm{~K}^{-1}\right)\end{array}$ \\
\hline$m_{\mathrm{w}}$ & weight of the reforming reactor $(\mathrm{g})$ \\
\hline$M_{\mathrm{F}}$ & molar holdup of the burner (mol) \\
\hline$P$ & pressure (atm) \\
\hline$Q_{\mathrm{F}}$ & heat input for preheating $\left(\mathrm{kJ} \mathrm{min}^{-1}\right)$ \\
\hline$r$ & rate of reaction $\left(\mathrm{mol} \mathrm{g}^{-1} \mathrm{~min}^{-1}\right)$ \\
\hline$S$ & ramp down slope \\
\hline$t_{\mathrm{d}}$ & pulse duration time \\
\hline$T$ & reaction temperature $(\mathrm{K})$ \\
\hline$T_{\mathrm{A}}$ & surrounding temperature $(\mathrm{K})$ \\
\hline$T_{\mathrm{f}}$ & temperature of the feed $(\mathrm{K})$ \\
\hline$T_{\text {in }}$ & inlet temperature of the reformer $(\mathrm{K})$ \\
\hline$T_{\mathrm{H} 1}$ & inlet temperature of the HTS1 (K) \\
\hline$T_{\mathrm{H} 2}$ & inlet temperature of the HTS2 (K) \\
\hline$T_{\mathrm{L}}$ & inlet temperature of the LTS $(\mathrm{K})$ \\
\hline$T_{\mathrm{P}}$ & inlet temperature of the PROX $(\mathrm{K})$ \\
\hline$T_{\mathrm{W}}$ & reactor wall temperature $(\mathrm{K})$ \\
\hline$U$ & heat transfer coefficient $\left(\mathrm{kJ} \mathrm{min}^{-1} \mathrm{~cm}^{-2} \mathrm{~K}^{-1}\right)$ \\
\hline$V_{R}$ & volume of the gas $\left(\mathrm{cm}^{3}\right)$ \\
\hline$W_{\text {cat }}$ & catalyst weight (g) \\
\hline$W_{\mathrm{S}}$ & carrier weight (g) \\
\hline$y$ & mole fraction \\
\hline \multicolumn{2}{|c|}{ Greek letters } \\
\hline$v$ & stoichiometric coefficient of the reaction \\
\hline$\rho$ & density of the carrier $\left(\mathrm{g} \mathrm{cm}^{-3}\right)$ \\
\hline$\rho_{\mathrm{av}}$ & $\begin{array}{l}\text { average density of the gas in the reforming reactor } \\
\left(\mathrm{g} \mathrm{cm}^{-3}\right)\end{array}$ \\
\hline
\end{tabular}

of Fig. 1. Next, the mixed reactant goes through the coil and then the burner before entering the ATR. The ATR effluent is passed to the gas cleaning units (HTS1, HTS2, PROX1-PROX3) as shown in Fig. 1. In the modeling phase, the experimental fuel processor is simplified to a reformer, a burner, three water gas shift reactors (HTS1, HTS2, LTS), and a preferential oxidation reactor (PROX) as shown in Fig. 2. Fresh feed containing methane, air, and water is fed into the reformer to carry out autothermal reforming (ATR). The reformer was integrated with a burner which supplies the heat needed for the reactions. The reformate is passed through a feed-effluent heat exchanger to the first high-temperature water-gas shift reactor (HTS1) followed by the second reactor (HTS2) and the to a low-temperature water-gas shift reactor (LTS). In these three reactors, $\mathrm{CO}$ was removed to meet the specification. Because the $\mathrm{CO}$ concentration out of the LTS was still too high, the preferential oxidation reaction (PROX) is performed. In the PROX reactors $\mathrm{O}_{2}$ injection devices are installed at the inlet of PROX, and $\mathrm{CO}$ is further oxidized to $\mathrm{CO}_{2}$, while, at the same time, some $\mathrm{H}_{2}$ is converted to $\mathrm{H}_{2} \mathrm{O}$.

\subsection{Reaction kinetics}

Table 1 shows the reactions occurred in the reformer, HTS 1 and HTS2, LTS, and PROX. As suggested by Lin et al. [16], a steady-state model describing the series of reactors has been constructed. With available experimental inlet and outlet temperatures and compositions, the kinetic parameters have been adjusted to describe experimental data. Let us use the reformer as an example. The pre-exponential factors are adjusted to match the experimental results while keeping the activation energies and adsorption constants unchanged. Hence, the data fitting algorithm of the reformer has the following steps:

(1) Starting with the SR pathway, the reactor wall inlet temperature, $T_{\mathrm{W}, \text { in }}$, is changed to match the outlet temperature of SR and the pre-exponential factors of $r_{1}$ and $r_{2}$ are adjusted to match the outlet component flow rates.

(2) While keeping the kinetics parameter of $r_{1}$ and $r_{2}$ fixed, $T_{\mathrm{W} \text {,in }}$ and pre-exponential factor of $r_{3}$ are varied to match the outlet temperature and component flows for the ATR pathway.

(3) Constrain $T_{\mathrm{W}, \text { in }}$ by establishing a linear equation to relate $T_{\mathrm{W}, \text { in }}(0)$ with $T_{\mathrm{in}}$.

(4) Modify kinetics parameters in $r_{1}$ and $r_{3}$ such that the errors are of the same order of magnitude for the SR and ATR pathways.

The procedure is repeated for HTS1, HTS2, LTS and PROX reactors. The rate expressions and corresponding parameter values are shown in Table 1 for the entire fuel processor.

\subsection{Dynamic modeling}

Homogenous reactor models were set up to describe the dynamic behavior of the experimental fuel processor [17]. The assumptions made include:

1. Constant pressure (1 bar).

2. Ideal gas behavior.

3. Same temperature for the vapor and solid phases.

4. Negligible thermal capacity for the gas phase in the reactor as compared to that of the solid catalyst and carrier.

5. Negligible heat loss for the HTS1, HTS2, LTS and PROX reactors.

Partial differential equations describing the energy and mass balances are lumped into $\mathrm{N}$ sections using the honeycomb carrier weight $\left(W_{\mathrm{S}}\right)$ as the independent variable (note that this also applies to the catalyst weight $W_{\text {cat }}$, become it is assumed that the catalyst is distributed uniformly throughout the carrier). Thus, 


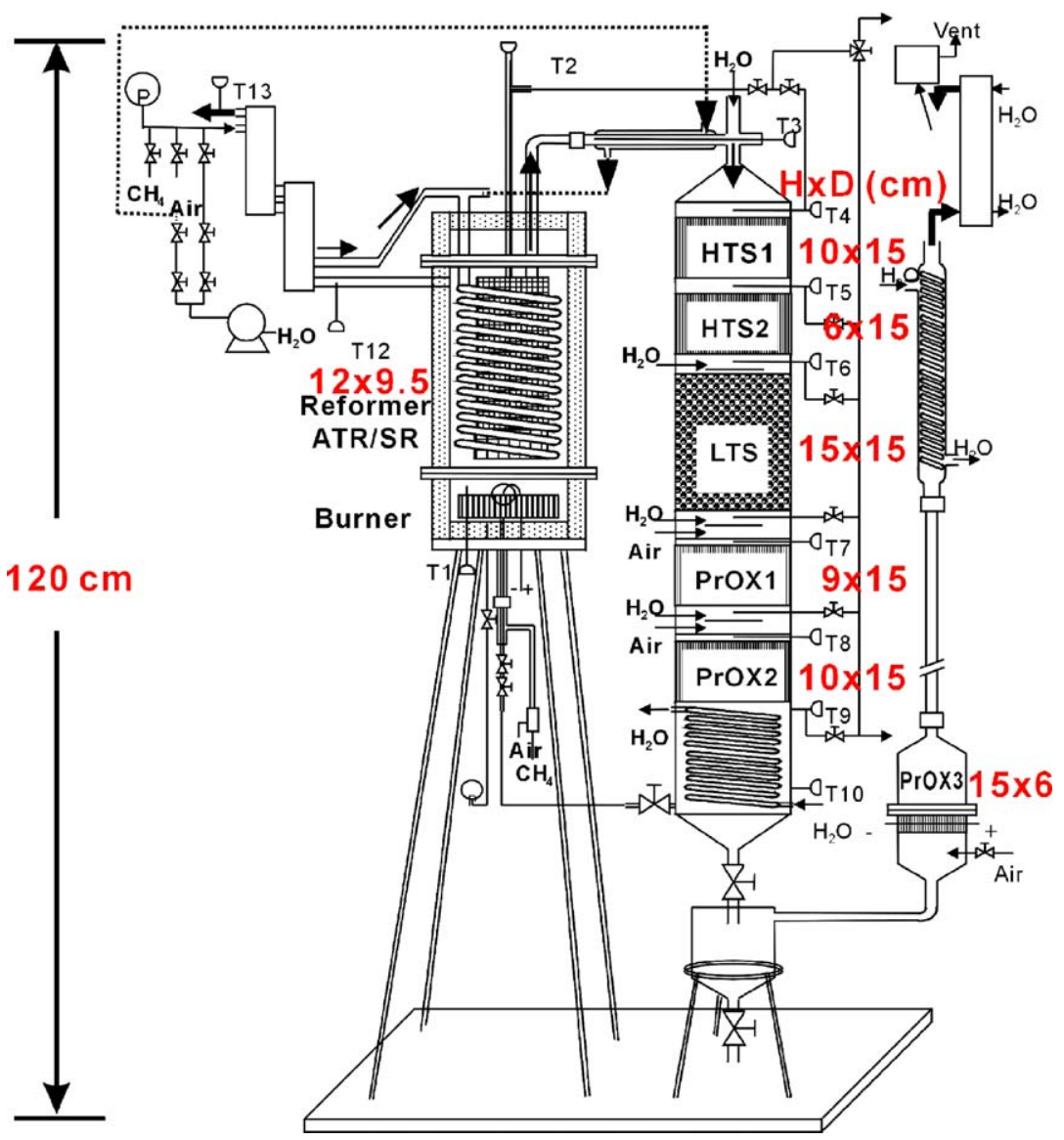

Fig. 1. Experimental fuel processor and corresponding dimensions.

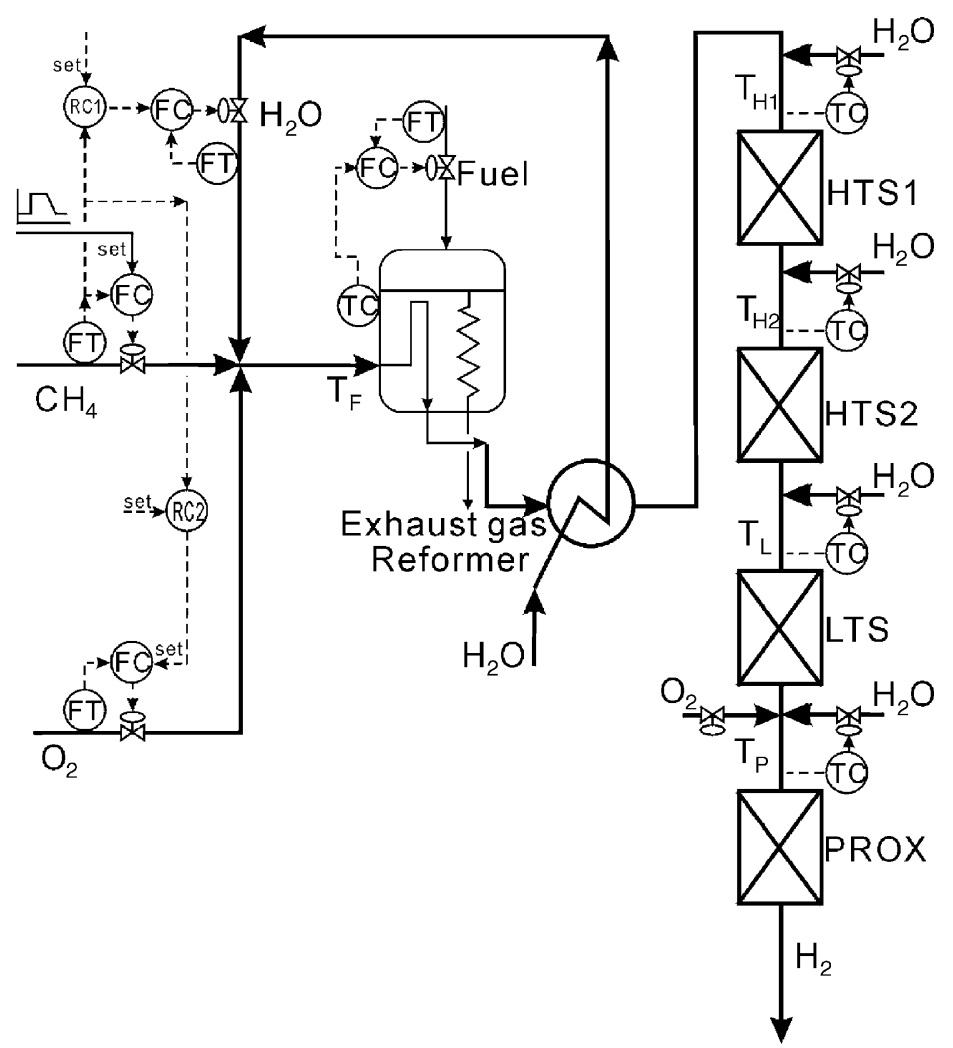

Fig. 2. Process configuration and control structure of the fuel processor. 
Table 1

Reaction rate expressions and parameter values for the fuel processor system

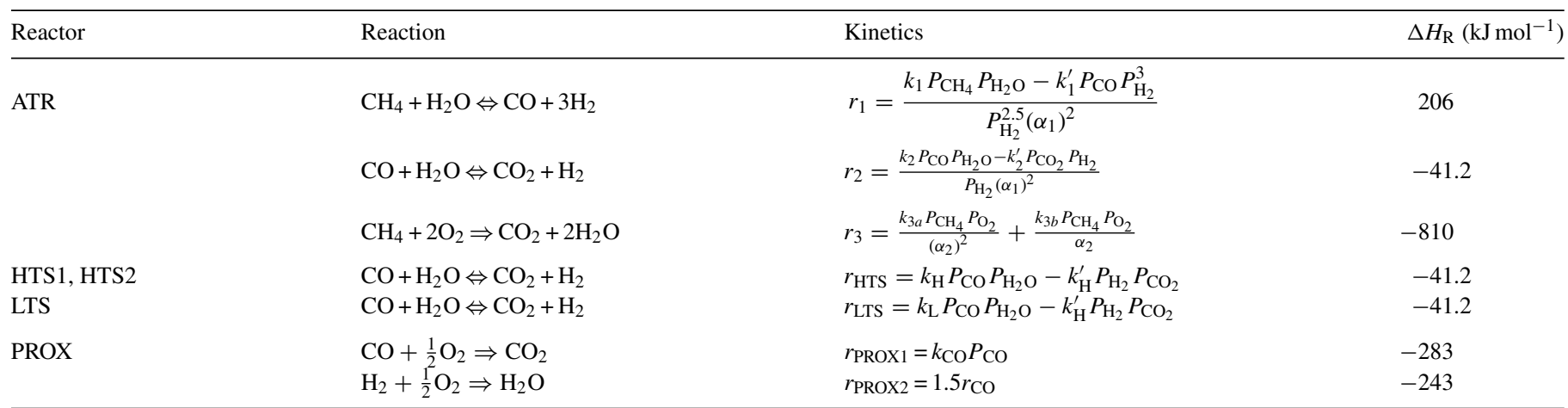

$\alpha_{1}=\left(1+K_{\mathrm{CO}} P_{\mathrm{CO}}+K_{\mathrm{H}_{2}} P_{\mathrm{H}_{2}}+K_{\mathrm{CH}_{4}} P_{\mathrm{CH}_{4}}+K_{\mathrm{H}_{2} \mathrm{O}} \frac{P_{\mathrm{H}_{2} \mathrm{O}}}{P_{\mathrm{H}_{2}}}\right), \alpha_{2}=\left(1+K_{\mathrm{CH}_{4}}^{\mathrm{OX}} P_{\mathrm{CH}_{4}}+K_{\mathrm{O}_{2}}^{\mathrm{OX}} P_{\mathrm{O}_{2}}\right)$ with $K_{\mathrm{CH}_{4}}=6.65 \times 10^{-4} \mathrm{e}^{4607 / T}, K_{\mathrm{CO}}=8.23 \times 10^{-5} \mathrm{e}^{8504 / T}$, $K_{\mathrm{H}_{2}}=6.12 \times 10^{-9} \mathrm{e}^{9971 / T}, K_{\mathrm{H}_{2} \mathrm{O}}=1.77 \times 10^{5} \mathrm{e}^{-10669 / T}, K_{\mathrm{CH}_{4}}^{\mathrm{OX}}=1.26 \times 10^{-1} \mathrm{e}^{3284 / T}$, and $K_{\mathrm{O}_{2}}^{\mathrm{OX}}=7.87 \times 10^{-7} \mathrm{e}^{11162 / T}$.

we have $N$ ordinary differential equations instead of one partial differential equation for each component material balance [18]. Consider the nth section in the axial direction. The energy balance of the reformer can be expressed as:

$$
\begin{aligned}
C_{p, \mathrm{~S}} W_{\mathrm{S}, n} \frac{\mathrm{d} T_{n}}{\mathrm{~d} t}= & F_{n-1} C_{p, n-1} T_{n-1}-F_{n} C_{p, n} T_{n} \\
& -W_{\mathrm{cat}, n} \sum_{j} \Delta H_{\mathrm{R}, j}^{\circ} r_{n, j}-\frac{4 U\left(T_{n}-T_{\mathrm{W}, n}\right) W_{\mathrm{S}, n}}{\rho_{\mathrm{S}} D_{1}}
\end{aligned}
$$

where $C_{p, \mathrm{~S}}$ is the heat capacity of the carrier, $W_{\mathrm{S}, n}$ the weight of the carrier, $T_{n}$ and $T_{\mathrm{W}, n}$ the reaction temperature and reactor wall temperature in the $n$th lump, respectively, $F_{n}$ the total molar flow rate at the $n$th lump, $C_{p, n}$ the heat capacity of the gas in the $n$th lump, $W_{\text {cat }, n}$ the weight of the catalyst in the $n$th lump, $r_{n, j}$ the reaction rate of the $j$ th reaction at the $n$th section, $\Delta H_{\mathrm{R}, j}$ the heat of reaction for the $j$ th reaction, $U$ the overall heat transfer coefficient, $D_{\mathrm{I}}$ the inner-diameter of the reactor, and $\rho_{\mathrm{S}}$ is the density of the carrier. The component material balance for the $i$ th composition becomes

$\rho_{\mathrm{av}} V_{R, n} \frac{\mathrm{d} y_{n, i}}{\mathrm{~d} t}=F_{n-1} y_{n-1, i}-F_{n} y_{n, i}+W_{\mathrm{cat}, n} \sum_{j} \nu_{i j} r_{n, j}$

where $\rho_{\mathrm{av}}$ is the averaged density of the gas in the reforming reactor, $V_{R, n}$ the volume of the gas in the $n$th lump of the reformer, $v_{i, j}$ the stoichiometric coefficient of the $i$ th component under $j$ th reaction, and $y_{n, i}$ is the mole fraction of the $i$ th component in the $n$th lump. Similarly, the reactor metal wall temperature can be expressed as

$$
\begin{aligned}
m_{\mathrm{W}, n} C_{p \mathrm{~W}, n} \frac{\mathrm{d} T_{\mathrm{W}, n}}{\mathrm{~d} t}= & k_{\mathrm{cond}} A_{\mathrm{L}}\left(T_{\mathrm{W}, n-1}-T_{\mathrm{W}, n}\right) \\
& +\frac{4 U\left(T_{n}-T_{\mathrm{W}, n}\right) W_{\mathrm{S}, n}}{\rho D_{\mathrm{I}}} \\
& +\frac{4 U\left(T_{\mathrm{A}}-T_{\mathrm{W}, n}\right) W_{\mathrm{S}, n}}{\rho D_{\mathrm{o}}}
\end{aligned}
$$

where $m_{\mathrm{W}, n}$ is the weight of the metal reactor wall in the $n$th lump, $C_{p \mathrm{~W}, n}$ the heat capacity of the metal reactor wall, $k_{\mathrm{cond}}$ the thermal conductivity of the reactor wall, and $D_{\mathrm{O}}$ is the outerdiameter of the reforming reactor. $T_{\mathrm{A}}$ represents the ambient temperature. The inlet temperature of the reformer is heated by a burner and the equation becomes

$C_{p, \text { avg }} M_{\mathrm{F}} \frac{\mathrm{d} T_{\text {in }}}{\mathrm{d} t}=Q_{\mathrm{F}}+F \sum y_{i} C_{p, i}\left(T_{\mathrm{f}}-T_{\mathrm{in}}\right)$

where $C_{p \text {,avg }}$ is the averaged heat capacity of the feed, $M_{\mathrm{F}}$ the molar holdup of the burner, $Q_{\mathrm{F}}$ the heat needed for preheating, and $T_{\mathrm{f}}$ is the temperature of the fresh feed. Relationship between the reactor inlet temperature $T_{\text {in }}$ ( $T_{0}$ is the lumped notation) and the reactor wall temperature at the inlet $\left(T_{\mathrm{W}, 0}\right.$ is the lumped notation) is established from a regression model of [16]. The energy balance equations describing the burner provide the inlet conditions for the reformer gas and metal wall temperatures.

Similarly, the equations describing water gas shift reactor and PROX can be derived. The energy balance equation becomes

$$
\begin{aligned}
C_{p, \mathrm{~S}} W_{\mathrm{S}, n}\left(\frac{\mathrm{d} T}{\mathrm{~d} t}\right)= & F_{n-1} C_{p, n-1} T_{n-1}-F_{n} C_{p, n} T_{n} \\
& -W_{\mathrm{cat}, n} \sum_{j} \Delta H_{\mathrm{R}, j}^{\circ} v_{i j} r_{n, j}
\end{aligned}
$$

and the component material balance equation is

$\rho_{\mathrm{av}} V_{R, n} \frac{\mathrm{d} y_{n, i}}{\mathrm{~d} t}=F_{n-1} y_{n-1, i}-F_{n} y_{n, i}+W_{\mathrm{cat}, n} \sum_{j} v_{i j} r_{n, j}$

The modeling equations of the HTS1, HTS2, LTS and PROX were assumed to be adiabatic and they were simpler than the modeling equation of the reformer.

The rate expressions of the reactions $\left(r_{j}\right)$ that take place in the fuel processor are obtained form the regression of the experimental data [14]. For the sake of completeness, the rate expressions are given in Table 1 and corresponding parameter values are shown in Table 2. Table 3 summarizes steady-state operating condition with $\mathrm{H}_{2} \mathrm{O} / \mathrm{CH}_{4}$ feed ratio of $1.45, \mathrm{O}_{2} / \mathrm{CH}_{4}$ feed ratio of 0.45 while the reformer inlet temperature was set to $717^{\circ} \mathrm{C}$ [14].

Before getting into the simulation results, it is also important to note that a heat-integration scheme can be applied to 
Table 2

Kinetic data from regression of an experimental methane fuel processor

\begin{tabular}{llll}
\hline Reactor & Reaction & $\begin{array}{l}\text { Pre-exponential } \\
\text { factor, } a_{0}\end{array}$ & $\begin{array}{l}\text { Activation energy } \\
\left(\mathrm{kJ} \mathrm{mol}^{-1}\right)\end{array}$ \\
\hline ATR & $r(1)$, forward $k_{1}$ & $6.32 \times 10^{16}$ & 240.1 \\
& $r(1)$, reverse $k_{1}^{\prime}$ & $1.759 \times 10^{3}$ & 17.0 \\
& $r(2)$, forward $k_{2}$ & $2.77 \times 10^{6}$ & 67.1 \\
& $r(3)$, forward $k_{3 a}$ & $1.56 \times 10^{8}$ & 86.0 \\
\multirow{2}{*}{ HTS } & $r(3)$, forward $k_{3 b}$ & $1.31 \times 10^{8}$ & 86.0 \\
& $r_{\text {HTS }}$, forward $k_{\mathrm{H}}$ & $9.886 \times 10^{5}$ & 47.4 \\
LTS & $r_{\text {HTS }, \text { reverse } k_{\mathrm{H}}^{\prime}}$ & $1.32 \times 10^{-2}$ & 38.1 \\
& $r_{\text {LTS }}$, forward $k_{\mathrm{L}}$ & $1.285 \times 10^{6}$ & 47.4 \\
PROX & $r_{\text {LTS }}$, reverse $k_{\mathrm{L}}^{\prime}$ & $1.32 \times 10^{-2}$ & 38.1 \\
& $r_{\text {PROX }}$, forward $k_{\text {PROX }}$ & $1.34 \times 10^{4}$ & 8.3 \\
\hline
\end{tabular}

save the fuel consumption. This is especially true at the start-up stage. The reason is that before the $\mathrm{CO}$ concentration reaches $45 \mathrm{ppm}$ level, hydrogen is recycled back to the burner to be used as the fuel while the remaining portion of hydrogen is used to preheat the feed. Fig. 1 shows that the inlet temperature to the reformer is controlled by manipulating the fuel flow rate while a valve position control is installed to ensure minimal utilization of external fuel by adjusting the hydrogen flow rate into the burner while the remaining hydrogen is passed through feedeffluent heat exchanger (FEHE) to provide additional preheating [19].

\subsection{Simulation results}

The ordinary differential equations (ODE; Eqs. (1)-(6)) describing the fuel processor are solved as the initial value problem using Euler method. The ODEs are programmed in FORTRAN and a typical simulation run takes about 2 min using IBM PC with Pentium 4 processor.
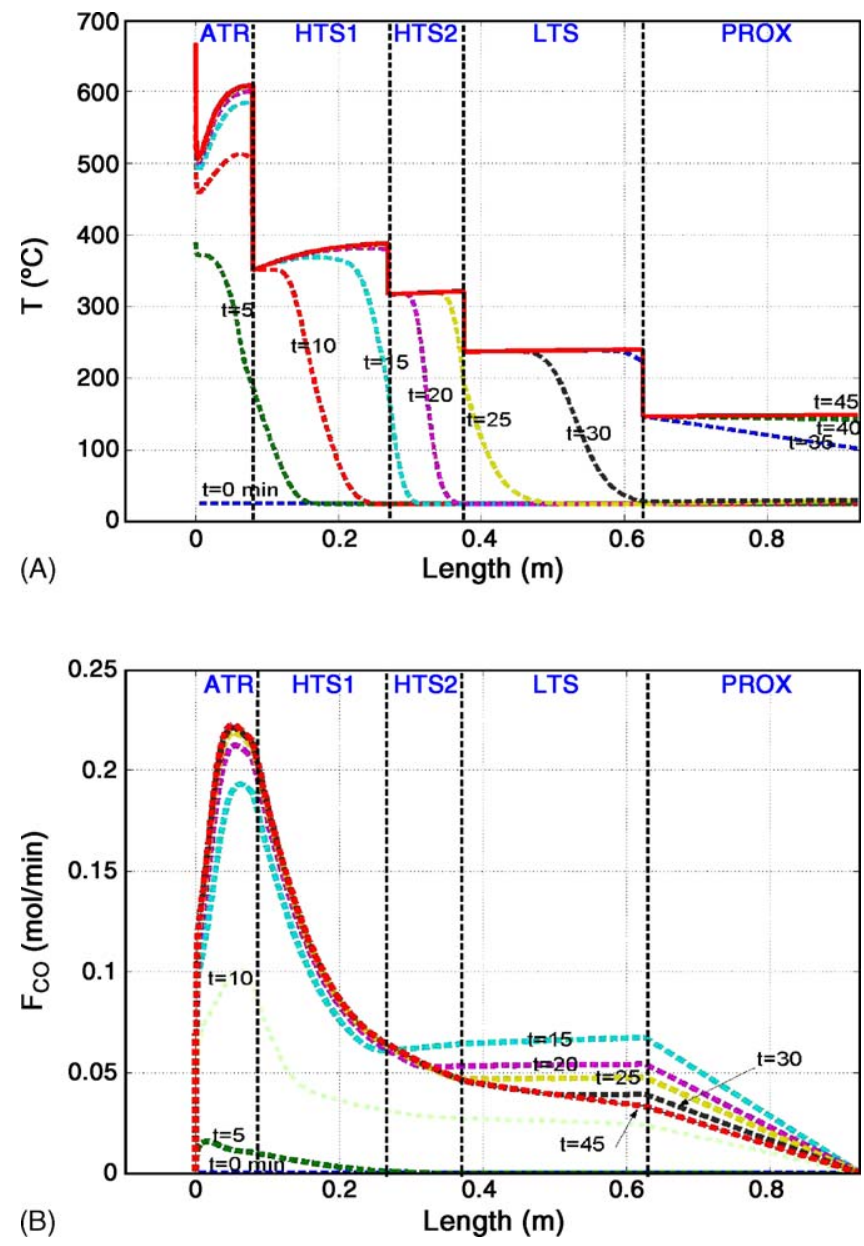

Fig. 3. The temperature and concentration profile of the reactor.

Table 3

Steady-state operating condition for fuel processor system

\begin{tabular}{|c|c|c|c|c|c|c|c|c|}
\hline & $T\left({ }^{\circ} \mathrm{C}\right)$ & $\mathrm{CH}_{4}\left(\mathrm{~mol} \mathrm{~min}^{-1}\right)$ & $\mathrm{H}_{2} \mathrm{O}\left(\mathrm{mol} \mathrm{min}^{-1}\right)$ & $\mathrm{CO}\left(\mathrm{mol} \mathrm{min}^{-1}\right)$ & $\mathrm{CO}_{2}\left(\mathrm{~mol} \mathrm{~min}^{-1}\right)$ & $\mathrm{O}_{2}\left(\mathrm{~mol} \mathrm{~min}^{-1}\right)$ & $\mathrm{H}_{2}\left(\mathrm{~mol} \mathrm{~min}^{-1}\right)$ & $\mathrm{N}_{2}\left(\mathrm{~mol} \mathrm{~min}^{-1}\right)$ \\
\hline \multicolumn{9}{|l|}{ ATR } \\
\hline Inlet & 717 & 0.480 & 0.696 & 0 & 0 & 0.216 & 0 & 0.812 \\
\hline Outlet & 650 & 0.015 & 0.413 & 0.274 & 0.191 & 0.03 & 1.21 & 0.812 \\
\hline Cooling & - & - & 0.486 & - & - & - & - & - \\
\hline \multicolumn{9}{|l|}{ HTS1 } \\
\hline Inlet & 350 & 0.015 & 0.898 & 0.274 & 0.191 & 0.03 & 1.210 & 0.812 \\
\hline Outlet & 402 & 0.015 & 0.710 & 0.081 & 0.390 & 0.03 & 1.410 & 0.812 \\
\hline Cooling & - & - & 0.200 & - & - & - & - & - \\
\hline \multicolumn{9}{|l|}{ HTS2 } \\
\hline Inlet & 317 & 0.015 & 0.910 & 0.081 & 0.390 & 0.03 & 1.410 & 0.812 \\
\hline Outlet & 322 & 0.015 & 0.880 & 0.059 & 0.410 & 0.03 & 1.427 & 0.812 \\
\hline Cooling & - & - & 0.220 & - & - & - & - & - \\
\hline \multicolumn{9}{|l|}{ LTS } \\
\hline Inlet & 237 & 0.015 & 1.110 & 0.059 & 0.410 & 0.03 & 1.427 & 0.812 \\
\hline Outlet & 241 & 0.015 & 1.090 & 0.043 & 0.420 & 0.03 & 1.440 & 0.812 \\
\hline Cooling & - & - & 0.270 & - & - & - & - & - \\
\hline \multicolumn{9}{|l|}{ PROX } \\
\hline Inlet & 150 & 0.015 & 1.360 & 0.043 & 0.420 & 0.03 & 1.440 & 0.812 \\
\hline Outlet & 320 & 0.015 & 1.360 & $1.3 \times 10^{-4}$ & 0.470 & 0.011 & 1.380 & 0.812 \\
\hline
\end{tabular}


Fig. 3 shows a cold start-up of ATR pathway. Initially, the reactor beds are at room temperature $\left(25^{\circ} \mathrm{C}\right)$ and the inlet of the reformer is heated up with the external fuel followed by the recycled hydrogen. The temperature front propagates through the reformer toward the HTS1 after 5 min. into the start-up. After $t=15 \mathrm{~min}$, the temperature front passes through HTS2 and to LTS at $t=25 \mathrm{~min}$. Thirty minutes after the startup, the temperature front propagates through PROX as shown in Fig. 3A. The total CO flow propagates at a slightly slower rate. It reaches an almost static profile $30 \mathrm{~min}$ after the startup. It is also important to note that the water gas shift reactors (HTS1, HTS2, and LTS) will become effective when the reactor temperatures approach nominal steady-state value (Fig. 3B). It is interesting to note that the CO concentration at the LTS effluent goes through a non-monotonic change. At $t \sim 15 \mathrm{~min}$, the total $\mathrm{CO}$ flow rate approaches a maximum, because of the production of the CO from the reformer. As the HST1, HTS2, and LTS become effective, the CO concentration is brought down and, eventually, reaches acceptable level after $t>30$ min.

Note that the temperature and concentration profiles in Fig. 3 is plotted in the reactor axial position with the actual dimension in the reactor length. Fig. 3 reveals the inherent dynamics of the fuel processor and it indicates without any adjustment in operating condition, it takes more than $30 \mathrm{~min}$ for the reactors to reach steady-state profiles.

\section{Sensitivity analysis}

Simulation results in Fig. 3 reveal that two factors play an important role in the start-up time of a fuel processor. One is the temperature of the catalyst bed, and the other is the composition, $\mathrm{CO}$ concentration in particular, at the effluent of the PROX reactor. Because the reactors are in series cascade structure, if the reactor temperatures do not reach the designated reaction temperatures, the gas cleaning units may not be functioning fully and this results in higher $\mathrm{CO}$ concentration at the reactor outlet. Note that, the fuel cell system will not be in operation if the $\mathrm{CO}$ concentration at the outlet of the PROX reactor exceeds the specification, $45 \mathrm{ppm}$. The temperature propagation in the fuel processor starts from the ATR. Recall that we use a furnace to preheat the fresh feeds and when the temperature of the feeds reach the ATR reaction temperature (around $700{ }^{\circ} \mathrm{C}$ ), hydrogen is generated along with $\mathrm{CH}_{4}$, $\mathrm{H}_{2} \mathrm{O}, \mathrm{H}_{2}, \mathrm{CO}, \mathrm{CO}_{2}$ and air. The hot outlet gaseous stream of the ATR serves as a heat source which heats up the catalyst bed of the following reactors, HTS1, HTS2, LTS, and PROX.

Thus, it is important to devise a strategy such that the temperature front propagates rapidly down the gas cleaning units, while maintaining low $\mathrm{CO}$ concentration. In other words, the effect of $\mathrm{CO}$ concentration should also be taken into consideration when one is devising a workable start-up strategy. Without changing the process configuration, available manipulated variables include: $\mathrm{CH}_{4}$ feed flow, steam feed flow, and air feed rate. By manipulated variables, we mean the variables can be adjusted, typically via control signal applied on a control valve. They can be flow rates or ratios of two flow rates. The importance of manipulated variables for rapid start-up is explored via sensitivity analysis.

\subsection{Steam-to-carbon ratio}

First, let us examine the manipulated variable is the "steamto-carbon" (S/C) ratio. The $\mathrm{S} / \mathrm{C}$ is a flow ratio which is adjusted by varying the set point of a ratio controller ( $\mathrm{RCl}$ in Fig. 2). When $\mathrm{CH}_{4}$ flow rate is kept constant, a change in S/C implies adjusting the steam flow rate. Table 1 shows that the steam reforming is highly endothermic and water gas shift reaction is a mildly exothermic reaction. An increase in the S/C ratio favors the steam reforming reaction with less $\mathrm{CO}$ generation. Because the inlet temperature to the reformer is controlled using the furnace heat input, the heat ( $Q$ in Fig. 4) propagates down the gas cleaning units will increase. That is the heat capacity flow at the outlet of the reformer increases, as a result of energy content carried by additional steam. The increased heat input to the furnace can be compensated using the recycled hydrogen at the start-up stage. Also note that the outlet temperature of the reformer actually decreases. On the other hand, the $\mathrm{CO}$ concentration also decreases as a result of lowered reactor temperatures (Fig. 4). This is important, because an increase in the S/C ratio can provide higher heat flux for the ATR outlet stream, while keeping the $\mathrm{CO}$ concentration down.

\subsection{Air-to-carbon ratio}

The second likely manipulated variable is the air-to-carbon ratio where the air flow rate is adjusted while fixing $\mathrm{CH}_{4}$ and steam flow rates. This manipulated input is used by Springmann et al. [15] to speed up the start-up. Large excess of oxygen favors the partial oxidation reaction (Table 1) and the heat flux toward the gas cleaning unit goes up accordingly. The temperature at the ATR outlet also goes up as a result of highly exothermic partial oxidation reaction as shown in Fig. 4. However, a higher reactor temperature results in a higher equilibrium conversion for the steam reforming (generating more $\mathrm{CO}$ ) and a lower conversion for the exothermic water gas shift reaction (converting less $\mathrm{CO}$ to $\mathrm{CO}_{2}$ ). Thus, we have a higher $\mathrm{CO}$ concentration as shown in Fig. 4. Unlike changing S/C ratio, adjusting the air-to-carbon ratio has a positive effect on the heat flux $(Q)$ and a less favorable effect on CO concentration.

\section{3. $\mathrm{CH}_{4}$ flow rate}

Let us first examine the case when the methane feed flow rate is varied while keeping the water and air flow rates fixed. Similar to the case of adjusting air flow rate, both the heat flux $(Q)$ and ATR outlet $\mathrm{CO}$ concentration increase (Fig. 4). The reasons for that is a higher $\mathrm{CH}_{4}$ concentration favors the steam reforming and partial oxidation reaction (Table 1), so the temperature at the ATR outlet increases and the $\mathrm{CO}$ generated also shows a trend of increase.

An alternative is changing the $\mathrm{CH}_{4}$ flow rate while keeping the S/C and air-to-carbon ratios constant. Certainly, the heat 

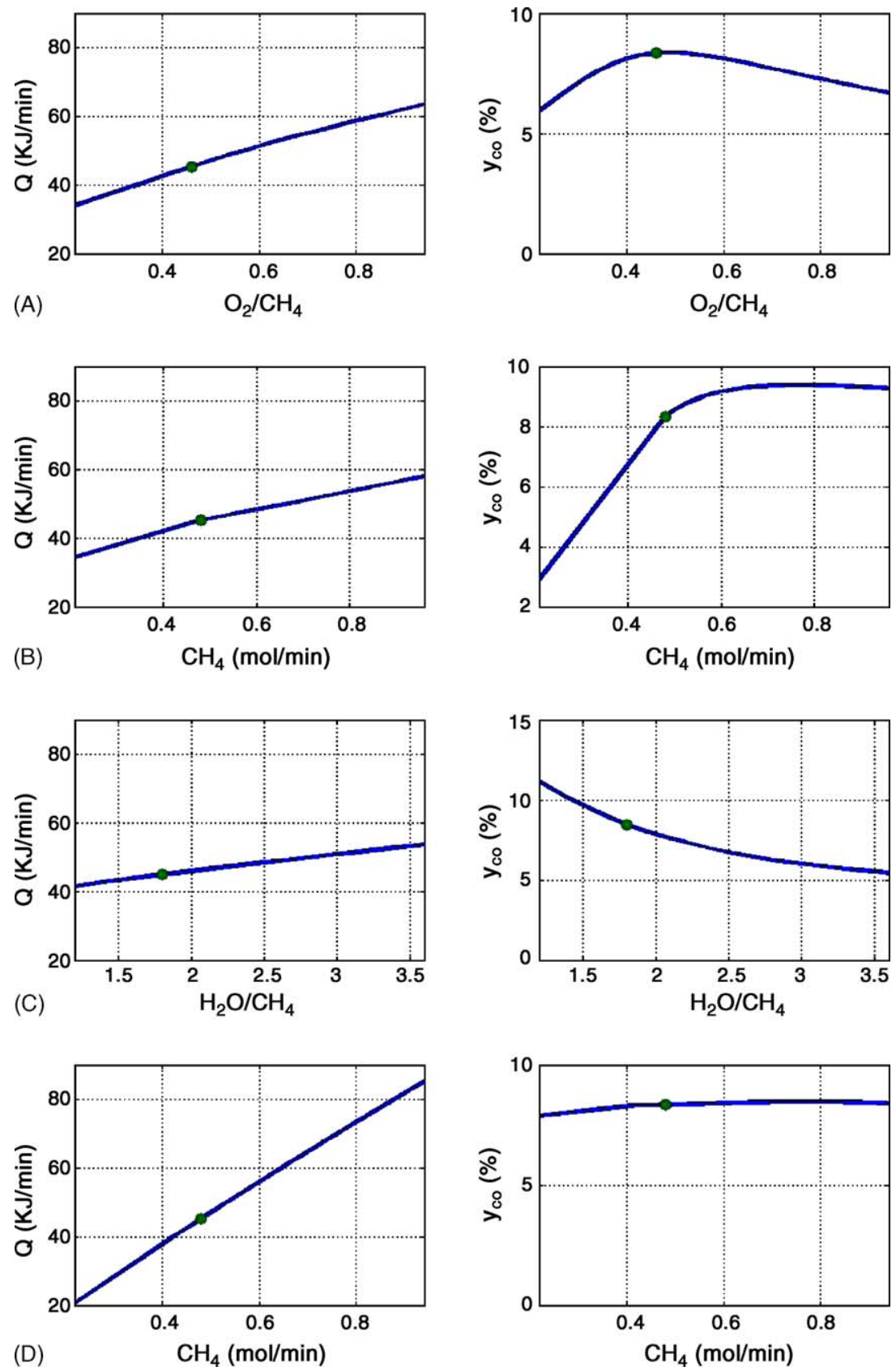

Fig. 4. Sensitivities of heat capacity flow rate $(Q)$ and $\mathrm{CO}$ concentration at the outlet of the ATR reactor by changing $(\mathrm{A})$ air-to-carbon ratio, $(\mathrm{B}) \mathrm{CH}_{4}$ flow rate, $(\mathrm{C})$ steam-to-carbon ratio, (D) $\mathrm{CH}_{4}$ flow rate while fixing air-to-carbon and steam-to-carbon ratios.

flux $(Q)$ increases as a result of an increase in the throughput. But the $\mathrm{CO}$ concentration is kept rather flat as the methane flow rate changes (Fig. 4). Another advantage of using this approach is that the feed ratios of start-up are the same as that of the normal operation. Thus, when switching back to the mode of nominal steady-state, only flow rate disturbance is experienced, instead of feed rate and feed ratio disturbances. Because we typically design the nominal operation condition with the flow rate set to a certain percentage (e.g., 50\%) of the maximum flow rate, keeping constant feed ratios is less likely prone to constraint violation while utilizing the system capacity fully.

\section{Start-up strategies}

\subsection{Control structure}

Before getting into the start-up strategies, the control structure for normal operation is examined first. Lin et al. [17] proposed two control structures to handle hydrogen production rate variations. One is the "on-supply" control structure where the $\mathrm{CH}_{4}$ feed flow is adjusted directly to meet the load demand. The other is the "on-demand"control structure $[20,21]$ where the hydrogen flow rate at the exit of the PROX reactor is set by the fuel cell demand and a pressure control is used to set the $\mathrm{CH}_{4}$ 

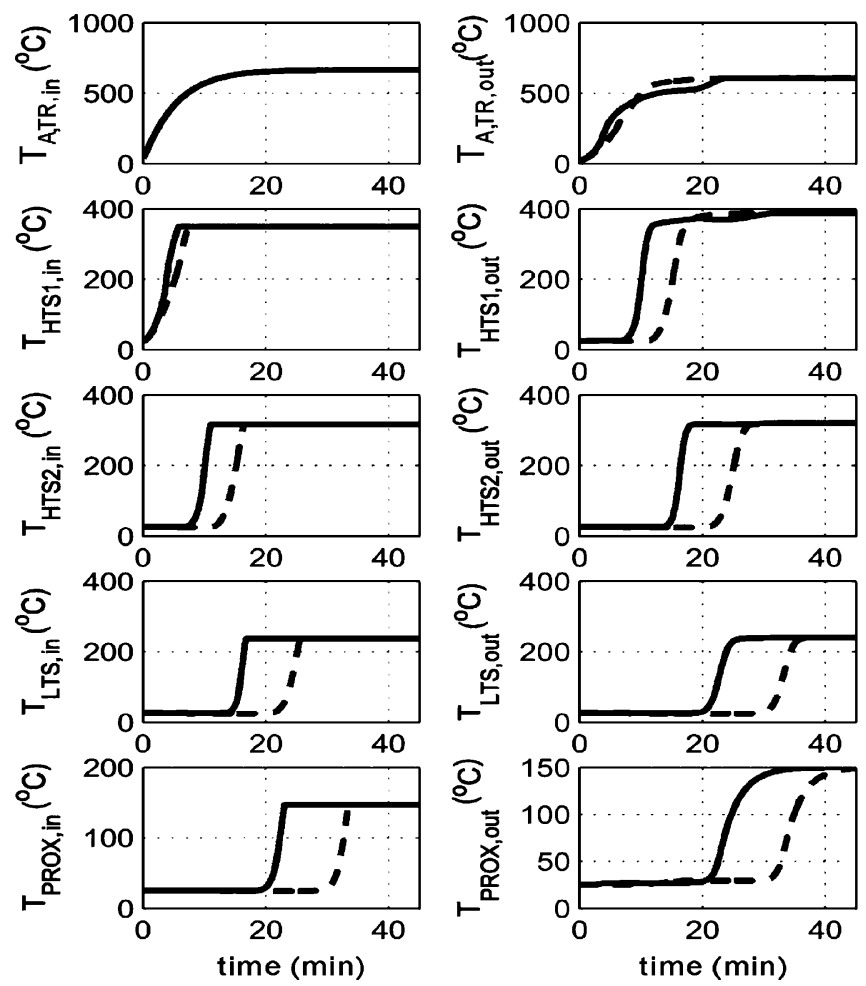
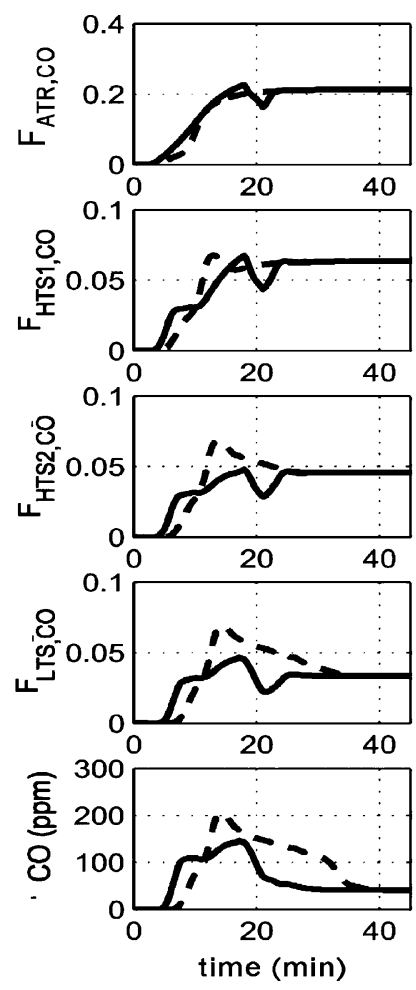
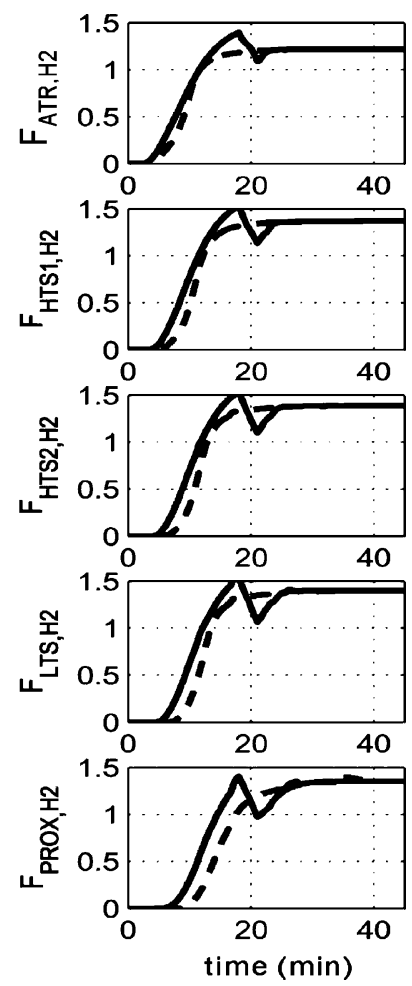

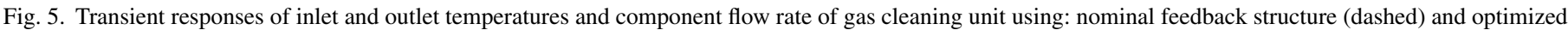
feed manipulation strategy (solid).

feed flow rate. The same control structure is used here, except that the pressure controller is put in manual mode at the start-up stage. Taking out a flow loop and a pressure loop, the control structure, at the start-up stage, consists of the following loops (Fig. 2):

1. $\mathrm{CH}_{4}$ feed is under flow control $\left(\mathrm{FC}\right.$ in $\mathrm{CH}_{4}$ flow path in Fig. 2).

2. $\mathrm{H}_{2} \mathrm{O}$ flow rate is ratio to $\mathrm{CH}_{4}$ feed rate ( $\mathrm{RC} 1$ in Fig. 2).

3. $\mathrm{O}_{2}$ flow rate is ratio to the $\mathrm{CH}_{4}$ feed flow (RC2 in Fig. 2).

4. Reformer inlet temperature is maintained by changing the fuel flow rate (TC providing the set point of the flow controller).

5. HTS1 (first high-temperature water-gas shift reactor), HTS2, LTS inlet temperatures are controlled by water injection.

6. PROX inlet temperature is maintained by varying water injection rate.

Fig. 2 shows the control structure with three flow loops, two ratio controllers, one temperature loop for fuel flow, four temperature loops for $\mathrm{H}_{2} \mathrm{O}$ addition. Note that instrument signals are depicted is dashed line in Fig. 2. At the start-up stage, the composition loop does not work until the process reaches to steady-state. Here, the set point of RC1 and RC2 are fixed. A third order lag with a time constant of $0.5 \mathrm{~min}$ is assumed for the reformer inlet temperature and the relay feedback test is used to find the ultimate gain and ultimate period [22]. The PI controller settings are obtained from Tyreus-Luyben tuning method [23]. In order to provide a basis for comparison, let us first examine the start-up time using the nominal control structure. That is all controllers are set to automatic when the fuel processor is switched on, i.e., without any designated start-up strategy. Simulation results, dashed line in Fig. 5, shows that it takes $37.5 \mathrm{~min}$ to reach operable steady-state, i.e., $\mathrm{CO}$ concentration meeting the $45 \mathrm{ppm}$ spec. Note that the long start-up time is due to large thermal masses of the HTS1, HTS2, LTS and PROX reactors and the limitation on the capacity of fuel flow of the experimental system. Despite all these limitations, it is possible to speed-up the cold start-up by feed manipulation.

\subsection{Feed manipulation}

Sensitivity analysis in Section 3 reveals two important factors to reduce the start-up time: (1) making the heat flux $Q$ as large as possible and (2) providing smooth transition back to the normal operating point. Looking at the steady-state heat flux and $\mathrm{CO}$

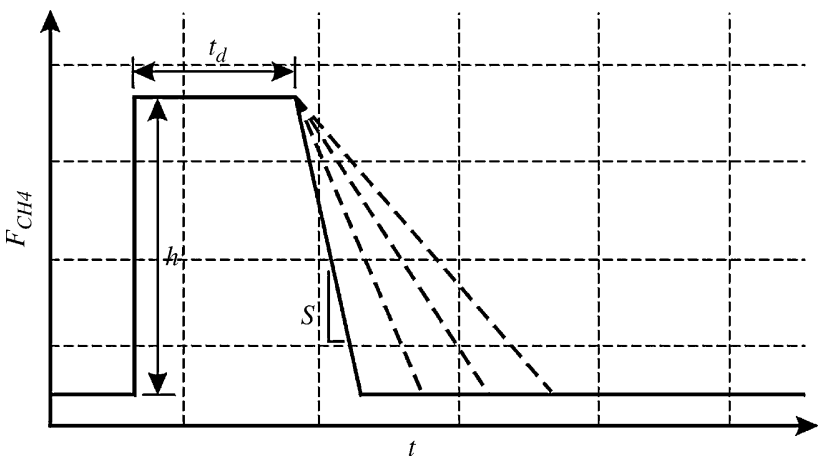

Fig. 6. Optimization variables, pulse height $(h)$, pulse duration $\left(t_{\mathrm{d}}\right)$, and ramp down slope $(S)$, for start-up time minimization. 
concentration effects in Fig. 4, the $\mathrm{CH}_{4}$ feed flow rate with fixed $\mathrm{S} / \mathrm{C}$ and air-to-carbon ratios seems to be an ideal candidate for reducing the start-up time. Assuming a pulse change in the feed flow as shown in Fig. 6, then the questions becomes:

1. What is the pulse height $(h)$ ?

2. What should be the pulse duration time $\left(t_{\mathrm{d}}\right)$ ?

3 . What is the appropriate slope $(S)$ ramping down to the normal operating point?

The answer to the first question is quite obvious. In order to get as much heat flux as possible, the feed is set to its maximum value, e.g., $F_{\mathrm{CH}_{4}}=F_{\mathrm{CH}_{4} \text {,max }}$. In a typical engineering design, the control valve is half-open at nominal flow rate. So the feed flow is doubled (from its nominal value) initially (Fig. 6).

Once the pulse height $(h)$ is fixed, the effect of the duration time $\left(t_{\mathrm{d}}\right)$ is explored next (Fig. 6). Let us use square pulses, i.e., ramp down slope $S$ approaching infinity, to illustrate the effects of duration time to the cold start-up. Fig. 7 shows dynamic responses temperatures, flows and concentration for three different duration times. As the pulse duration time increases, the temperature front propagates down the reactors (e.g., outlet temperature of PROX reactor) at a faster speed. But a negative step change, back to the nominal operating point, introduces additional disturbance which subsequently driving the $\mathrm{CO}$ con- centration out of spec. Fig. 7 shows that for the duration time of 10,18 , and $35 \mathrm{~min}$, the corresponding start-up times are $41.3,29.1$, and $33.7 \mathrm{~min}$, respectively. Two observations can be made immediately. First, a negative step change (resulted from a square pulse) is too large a disturbance for a stabilizing system. Second, there exists an optimal duration time. That is too small a duration time will slow down the temperature front propagation and too large a duration time makes the start-up time effective the same as the start-up with the nominal control structure (e.g., dashed line in Fig. 5).

Thus, the effects of ramp down slope are investigated. Assume the duration time is $t_{\mathrm{d}}=18 \mathrm{~min}$, three different ramp down rates, $(S=\Delta F / \Delta t=-\infty(-0.48 / 0),-0.096(-0.48 / 5)$, and $-0.024(-0.48 / 20))$, are simulated as shown in Fig. 8. Fig. 8 shows that for the duration slope of $\infty,-0.096$, and $-0.024 \mathrm{~min}$, the corresponding start-up times are 29.1, 28.8, and $29.8 \mathrm{~min}$, respectively. The results indicate that a large a slope introduces unnecessary disturbance in $\mathrm{CO}$ concentration and too small a slope lead to a sluggish response. Again, an optimal setting exists for the ramp down rate.

Instead of going through all possible combinations, the startup problem can be formulated as an optimization problem, provided the shape of feed manipulation (e.g., Fig. 6). The objective is to minimize the start-up time ( $\left.t_{\text {startup }}\right)$ which is defined as the time where $\mathrm{CO}$ concentration at PROX outlet reaches $45 \mathrm{ppm}$
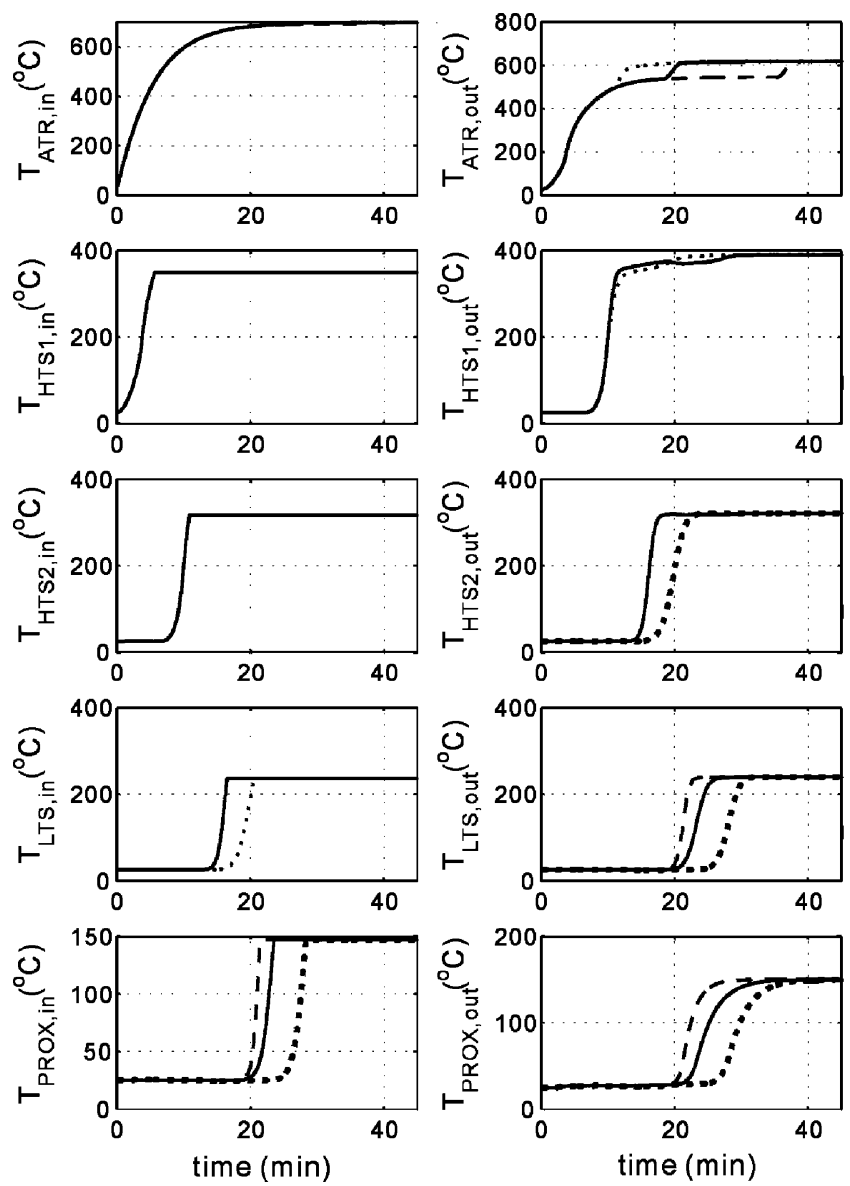
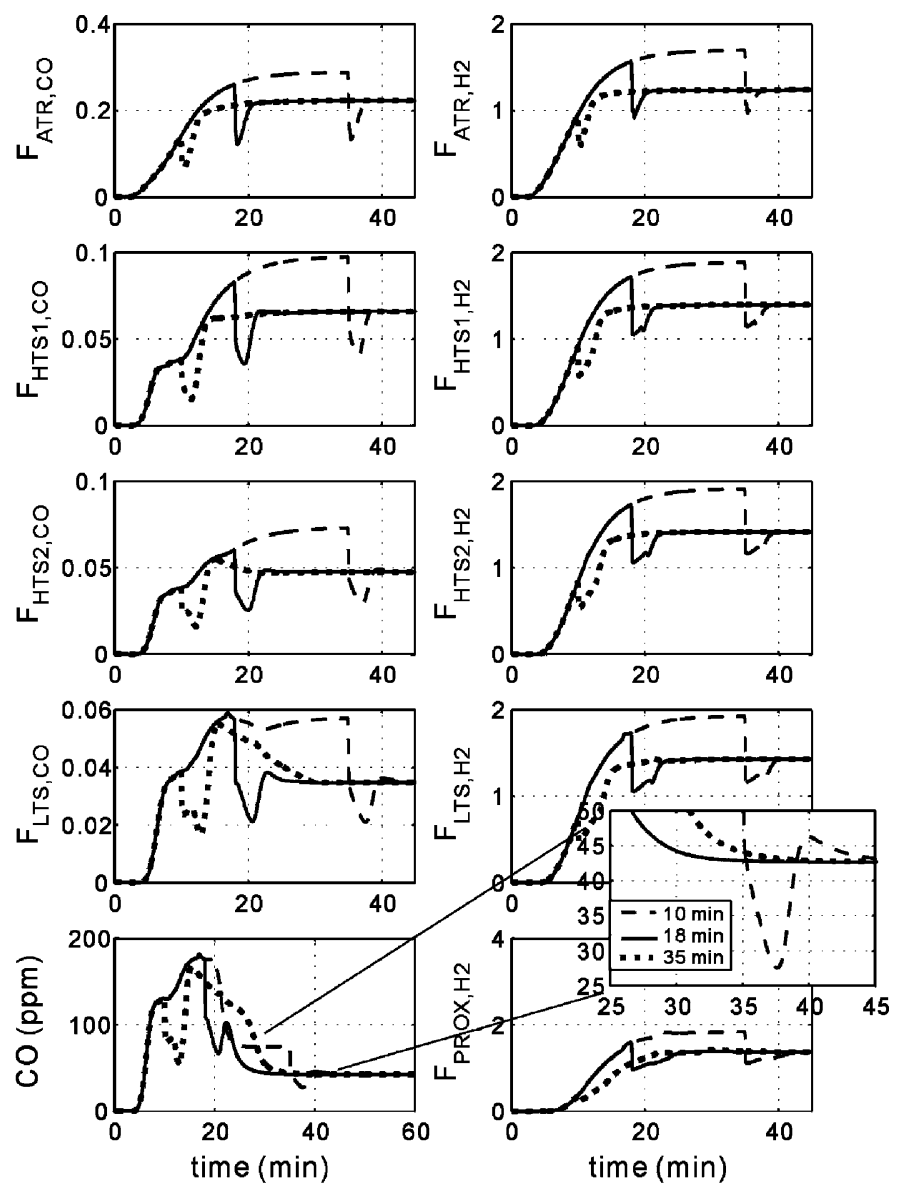

Fig. 7. Cold start-up of the fuel processor with pulse duration time of $10 \mathrm{~min}$ (dashed), $18 \mathrm{~min}$ (solid), and $35 \mathrm{~min}$ (dot). 

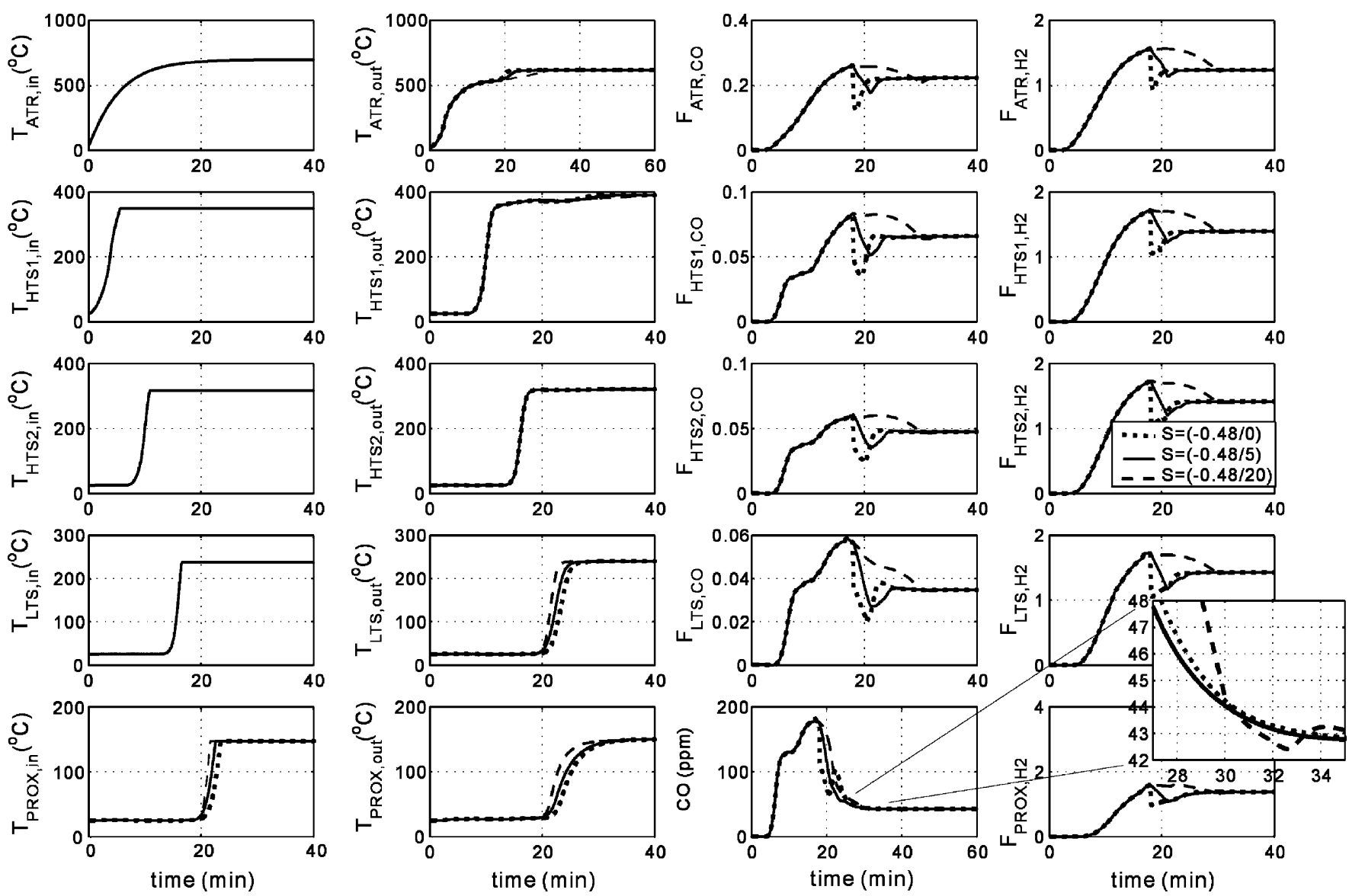

Fig. 8. Cold start-up of the fuel processor with ramp down slope of $-\infty$ (dot), -0.096 (solid), and -0.024 (dashed).

and remains below $45 \mathrm{ppm}$ for $t>t_{\text {startup. }}$. The optimization problem can be expressed as

$$
\begin{aligned}
& \min _{x \in \Omega} t_{\text {startup }}=f\left(h, t_{\mathrm{d}}, S\right), \quad \Omega=\left\{h, t_{\mathrm{d}}, S\right\} \\
& \text { subject to }\left\{h \leq h^{\max }\right\}
\end{aligned}
$$

where $h$ is the pulse height, $t_{\mathrm{d}}$ the duration time, $S$ the ramp down slope, and $h^{\max }$ is the allowable input change. The results show that optimal $t_{\mathrm{d}}$ and $S$ are $17 \mathrm{~min}\left(t_{\mathrm{d}}\right)$ and $-0.096(S)$, respectively. With this setting, simulation result, solid line in Fig. 5, shows that the start-up time can be reduced by a factor of $25 \%$ (as compared to the nominal control structure-based start-up, $t_{\text {startup }}=37.5 \mathrm{~min}$ ) and becomes $t_{\text {startup }}=28 \mathrm{~min}$.

\subsection{Heuristics}

Despite the fact that mathematical programming can be used to find the optimal start-up strategy, it will be helpful if an efficient start-up can be generated heuristically. Extensive simulation reveals that a suboptimal solution can be obtained using the following approach. Provided with the nominal operating condition, we have the following steps:

1. Set the $\mathrm{CH}_{4}$ feed flow to the maximum value. Note that the air and water flow rates also increase with the same ratio.
2. Identify the time (i.e., time $=t_{\text {ramp }}$ ) when the PROX inlet temperature starts to increase and also find the rate of the temperature change (i.e., $\Delta T_{\mathrm{PROX}} / \Delta t$ ).

3. Start to ramp down at $t_{\text {ramp }}$ with the slope $\Delta \bar{F}_{\mathrm{CH}_{4}} /\left[\left(\bar{T}_{\mathrm{PROX}}-\right.\right.$ $\left.25) / 2 /\left(\Delta T_{\mathrm{PROX}} / \Delta t\right)\right]$. That is the ramp down is completed when the reactor inlet temperature is half-way (i.e., $\left(\bar{T}_{\text {PROX }}-\right.$ $25) / 2$ ) to the steady-state value ( $\left.\bar{T}_{\mathrm{PROX}}\right)$.

With this start-up strategy, the result shows that the start-up dynamics is almost the same as that of the optimal one (solid line in Fig. 5) and the start-up time is $28 \mathrm{~min}$.

\subsection{Design modifications}

Up to this point, we have devised start-up strategies for an existing fuel processor (Fig. 1). The next question then becomes: can we speed up the start-up time further by design modification. From design perspective, two approaches are possible. One is to use the heat from the effluent of PROX reactor to heat up the inlet streams to HTS1, HTS2, LTS, and PROX, a typical heatintegration approach (Fig. 9). This can speed-up the temperature front propagation by providing heat at the reactor inlet. The second approach is associated with materials design. Recall that the inherent problem with large start-up time of the fuel processor is the heating rate. Because of the heat capacity of the air is quite 
(A)

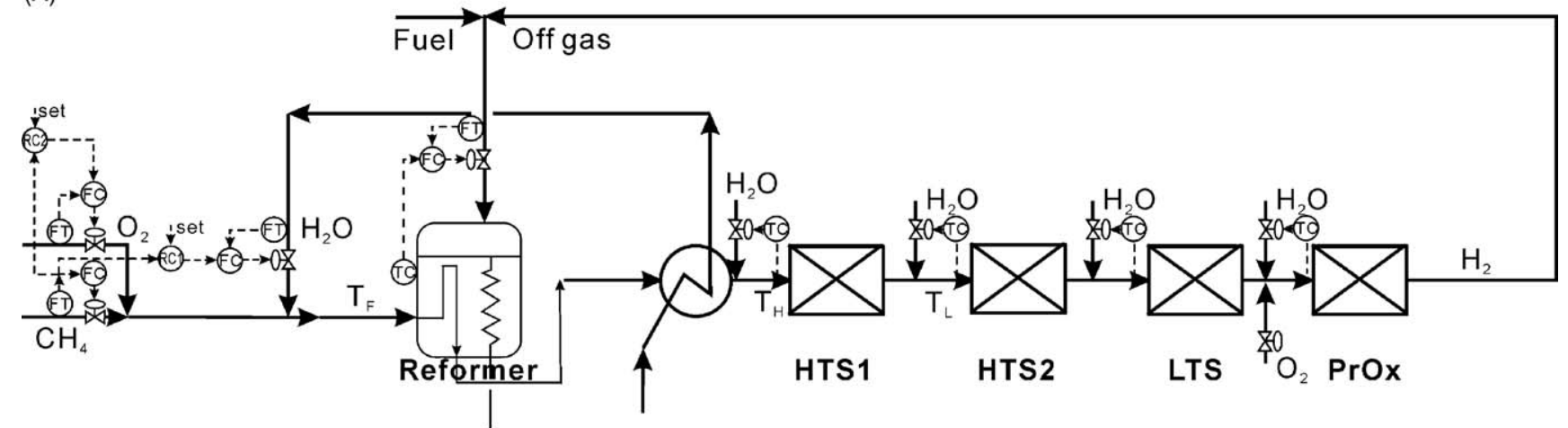

(B)

Exhaust gas

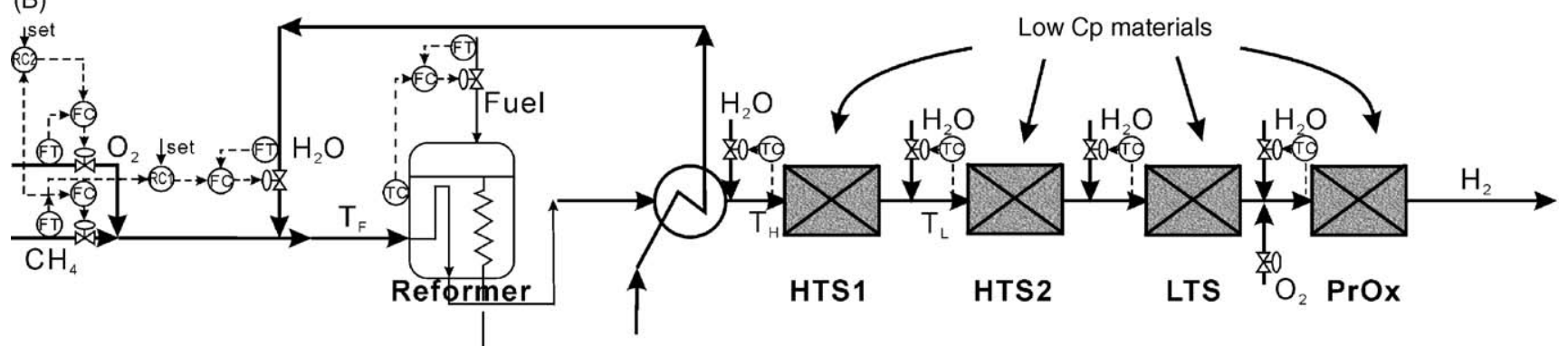

Exhaust gas

Fig. 9. Design modification: (A) heat integration scheme and (B) low- $C_{p}$ materials for the catalyst carriers.
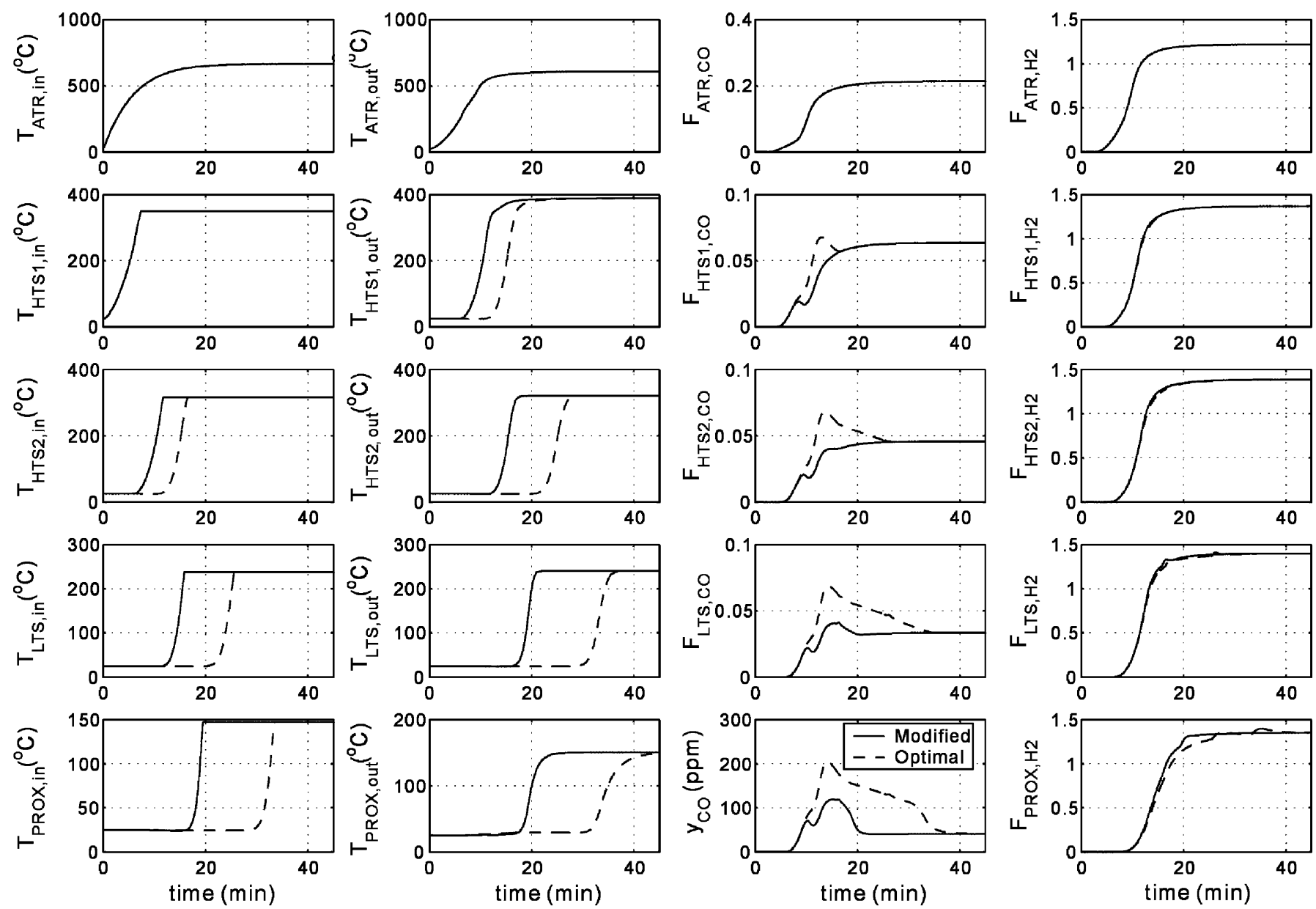

Fig. 10. Comparison of transition behavior of the fuel processor with: (A) low- $C_{p}$ material (solid) and (B) original design (dashed). 
small, the convective heating dominates the start-up time. If low heat capacity (low- $C_{p}$ ) materials can be used for the catalyst carrier, the start-up time can be reduced significantly. Consider the case when the heat capacity of the carrier is reduced to $50 \%$ of their original values. Simulation results, Fig. 10, show that temperature front is propagated at a much faster rate and the start-up time becomes $22 \mathrm{~min}$, a $42 \%$ reduction from the original design. Note that this is achieved using the nominal control structure for the start-up and further improvement is possible using the optimal feed policy as discussed earlier.

\section{Conclusion}

Cold start-up of a methane fuel processor is studied in this work. The experimental fuel processor is intended to provide hydrogen for a proton exchange membrane (PEM) fuel cell for the power generation $(3 \mathrm{kWe})$. A dynamic model consisting of a reformer, three water-gas shift reactors, and a preferential reactor are described. Two determining factors for a rapid startup are identified: speed of temperature front propagation and acceptable CO concentration. Steady-state analyses reveal that the fuel feed flow rate with fixed steam-to-carbon and air-tocarbon ratios is an ideal manipulated variable at the start-up stage. Considering both large initial heat flux for convective heat transfer and a gradual transition back to nominal operating point, the shape of feed manipulation is determined which is a pulse with a linear ramp down to the nominal value. With the feed scenario available, the fuel processor start-up can be formulated as a constrained optimization problem and can be solved numerically. From optimization result, a heuristic is generated for rapid start-up of a fuel processor. This leads to a $25 \%$ improvement in the start-up time. Finally, issues of design modification are explored for further reduction in the start-up time. The results show that if the low heat capacity materials are used for catalyst carriers, the start-up time can be reduced by a factor of $42 \%$.

\section{References}

[1] S. Ahmed, M. Krumpelt, Hydrogen from hydrocarbon fuels for fuel cells, Int. J. Hydrogen Energy 26 (2001) 291.

[2] Fuel Cell Handbook, EG\&G Services Parsons Inc., Science Applications International Corporation, 2000.

[3] J. Larminie, A.L. Dicks, Fuel Cell Systems Explained, Wiley, New York, 2000.
[4] J.H. Hirschenhofer, D.B. Stauffer, R.R. Engleman, M.G. Klett, Fuel Cell Handbook, DOE/FETC-99/1076, 4th ed., US Department of Energy, Federal Energy Technology Center, Morgantown, WV, 1998.

[5] C. Song, Fuel processing for low-temperature and high-temperature fuel cells. Challenges, and opportunities for sustainable development in the 21st century, Catal. Today 77 (2002) 17.

[6] R.J. Farrauto, R.M. Heck, Environmental catalysis into the 21st century, Catal. Today 55 (2000) 179.

[7] A.M. Meziou, I.M. Alatiqi, Identification and control of an industrial steam reforming plant, Can. J. Chem. Eng. 72 (1994) 321.

[8] I.M. Alatiqi, A.M. Meziou, G.A. Gasmelseed, Modeling, simulation and sensitivity analysis of steam-methane reformer, Int. J. Hydrogen Energy 14 (1989) 241.

[9] C.R.H. de Smet, M.H.J. de Croon, M.R.J. Berger, G.B. Marin, J.C. Schouten, Design of adiabatic fixed-bed reactors for the partial oxidation of methane to synthesis gas. Application to production of methanol and hydrogen-for-fuel-cells, Chem. Eng. Sci. 56 (2001) 4849.

[10] E.D. Doss, R. Kumar, R.K. Ahluwalia, M. Krumpelt, Fuel processors for automotive fuel cell systems: a parametric analysis, J. Power Sources 102 (2001) 1.

[11] Y. Choi, H.G. Stenger, Kinetics, simulation and insights for CO selective oxidation in fuel cell applications, J. Power Sources 129 (2004) 246.

[12] J.R. Lattner, M.P. Harold, Comparison of conventional and membrane reactor fuel processors for hydrocarbon-based PEM fuel cell systems, Int. J. Hydrogen Energy 29 (2004) 393.

[13] P. Beckhaus, A. Heinzel, J. Mathiak, J. Roes, Dynamics of $\mathrm{H}_{2}$ production by steam reforming, J. Power Sources 127 (2004) 294.

[14] M. Sommer, A. Lamm, A. Docter, D. Agar, Modelling and dynamic simulation of a fuel cell system with an autothermal gasoline reformer, J. Power Sources 127 (2004) 313.

[15] S. Springmann, M. Bohnet, A. Docter, A. Lammd, G. Eigenberger, Cold start simulations of a gasoline based fuel processor for mobile fuel cell applications, J. Power Sources 128 (2004) 13.

[16] S.T. Lin, Y.H. Chen, C.C. Yu, Y.C. Liu, C.H. Lee, Modeling of an experimental fuel processor, J. Power Sources 148 (2005) 43.

[17] S.T. Lin, Y.H. Chen, C.C. Yu, Y.C. Liu, C.H. Lee, Dynamic modeling and control structure design of an experimental fuel processor, Int. J. Hydrogen Energy 31 (2006) 413.

[18] F. Reyes, F.W.L. Luyben, Steady-state and dynamic effects of design alternatives in heat-exchanger/furnace/reactor processes, Ind. Eng. Chem. Res. 39 (2000) 3335 .

[19] Y.H. Chen, C.C. Yu, Design and control of heat-integrated reactors, Ind. Eng. Chem. Res. 42 (2003) 2791.

[20] W.L. Luyben, B.D. Tyreus, M.L. Luyben, Plantwide Process Control, McGraw-Hill, New York, 1999.

[21] Y.C. Cheng, K.L. Wu, C.C. Yu, Arrangement of throughput manipulator and inventory control in plantwide control, J. Chin. Inst. Chem. Eng. 33 (2002) 283.

[22] C.C. Yu, Autotuning of PID Controllers, 2nd ed., Springer-Verlag, London, 2006.

[23] B.D. Tyreus, W.L. Luyben, Tuning PI controllers for integrator-dead time processes, Ind. Eng. Chem. Res. 35 (1992) 3480 